\title{
On analysis and redesign of bolted L-flanged connections
}

\section{Pedersen, Niels Leergaard}

Published in:

Wind Energy

Link to article, DOI:

10.1002/we.2080

Publication date:

2017

Document Version

Peer reviewed version

Link back to DTU Orbit

Citation (APA):

Pedersen, N. L. (2017). On analysis and redesign of bolted L-flanged connections. Wind Energy, 20(6), 10691082. https://doi.org/10.1002/we.2080

\section{General rights}

Copyright and moral rights for the publications made accessible in the public portal are retained by the authors and/or other copyright owners and it is a condition of accessing publications that users recognise and abide by the legal requirements associated with these rights.

- Users may download and print one copy of any publication from the public portal for the purpose of private study or research.

- You may not further distribute the material or use it for any profit-making activity or commercial gain

- You may freely distribute the URL identifying the publication in the public portal

If you believe that this document breaches copyright please contact us providing details, and we will remove access to the work immediately and investigate your claim 


\title{
On Analysis and Redesign of Bolted
}

\section{L-Flanged Connections}

\author{
Niels Leergaard Pedersen \\ Dept. of Mechanical Engineering, Solid Mechanics \\ Technical University of Denmark
}

Nils Koppels Allé, Building 404, DK-2800 Kgs. Lyngby, Denmark

email: nlp@mek.dtu.dk

\begin{abstract}
In wind turbine towers the preferred design is circular tubes that are connected by a bolted flange joint. The design is typically that of an L-flange resulting in an eccentrically loaded bolted connection. The eccentricity results in a non-linear relationship between external load on the tower and the tensile force in the bolt. In the literature and also in standards different models are presented for this important non-linear response. In the present paper a simplified expression for the non-linear force response is presented based on finite element calculations using contact analysis. The L-flange connection is in essence a bad design because it leads to a non-optimal ratio between external force and bolt force. Furthermore bolt bending results in an even higher bolt stress resulting in a reduction of strength. The present paper presents simple modifications of the L-flange design that considerably improves the connection strength.
\end{abstract}

Key words: L-flange, bolt, eccentric, contact, design, FE. 


\section{Introduction}

Bolted connections are one of the most important assembly methods in relation to both mechanical engineering and civil (structural) engineering. In civil engineering the typical use of bolted connections is in assembly of steel structures e.g. the supporting structure of buildings but also for wind turbine towers. In some structural cases the bolt is used as a cross pin i.e. no connection preload is introduced to improve the fatigue strength. The different sections of wind turbine towers are typically tubular, and the sections are bolted together with preloaded bolts, see e.g. [1] for an overview. The preload is important for the connection strength between the different tubular tower sections, these connections are primarily loaded by a varying bending moment (both direction and size) and the nacelle weight.

In a traditional preloaded bolted connection the fatigue strength is controlled primarily by the bolt load amplitude, the mean stress size is not important as long as the total stress size is below the yield stress. The ratio $\Phi$ of the external load on the structure that is transmitted to the bolt is controlled by the clamped members stiffness, $K_{m}$, relative to the bolt stiffness, $K_{b}$.

$$
\Phi=\frac{K_{b}}{K_{b}+K_{m}}
$$

The stiffness calculation can be found in e.g. the standard [2]. A general discussion of the different models for calculating the stiffnesses can be found in e.g. [3] and references therein. In relation to re-design and different points of attack for the external load see e.g. [4] and [5]. The ratio $\Phi$ is typically a small number say 0.1 , i.e., only $10 \%$ of the external load is transmitted to the bolt. This holds true as long as there is a clamping force between the members. With concentric load the relationship between external load and transmitted load to the bolt is linear, this is also the case for eccentric load as long as the boundary condition, i.e. the contact area between the clamped members, is constant. For an eccentric load this is typically only valid for 
a relatively small external load (relative to the preload). With the changing boundary condition we have a non-linear relationship.

The L-flange is an example of an eccentrically loaded connection and many papers in the literature are related specifically to this connection type, see e.g. [6], [7], [8], [9], [10] and [11]. The standard [2] also specifies a calculation method for these eccentrically loaded connections. One of the main problems of the L-flange connection is that the relationship between external load and bolt load is not favorable for a large part of the application range.

In Figure 1 a typical L-flange connection is shown. Various connection types (not shown) are possible between the tower wall and the flange, see e.g., [1], leading to different problems with stress concentration which will not be discussed in the present paper.

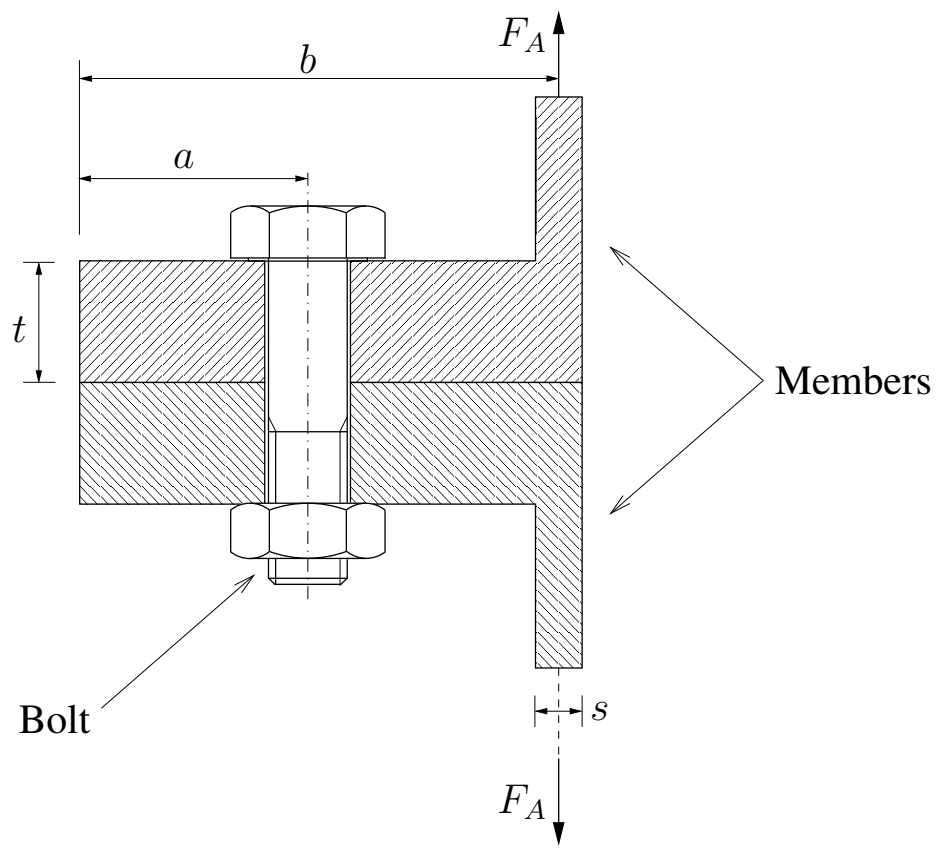

Figure 1: Bolted L-flange connection shown with dimensions and eccentric external load.

The relationship between an increase in external load $F_{A}$ and the increase in bolt load is first linear with a favorable ratio much like the concentrically loaded connection. With higher values of $F_{A}$ the relationship is non-linear as the boundary condition (contact) changes. Finally for relatively large external load values the contact conditions do not change anymore and therefore 
we have again a linear relation, in principle the connection acts finally as if there is no preload.

For a concentric connection the loss of clamping force between members result in a one to one correspondence between increase in external load and increase in bolt load. For the Lflange connection high external load values results in that the increase in bolt load is controlled by the ratio $\Phi_{l}$.

$$
\Phi_{l}=\frac{b}{a}
$$

which is not favorable. In the above derivation the bolt bending is neglected, we also assume linear elasticity. Plastic deformation will change the result for high bolt stress values but this is not within the application range suitable for the connection.

The standard bolted design with concentric load is directly by the layout an excellent design and to improve the design we must improve the stiffness ratio or alternatively reduce the stress concentration in the bolt as it can be found in e.g. [12] and [13]. For the L-flange the strength improvement can also be done by bolt thread shape optimization, however more significant improvements in strength are found by design modifications made to the connection.

The present paper focus on two points:

- The transfer function between external load and bolt force for L-flange joints.

- Simple design modifications for improving the strength.

In relation to the first bullet many different transfer functions are presented in the literature, some based on beam models and some on finite element (FE) calculations. In [11] many of the different models are presented and compared. From the comparison it is clear that the variation is rather large, the problems being that for some designs the proposed models either over or under estimate the bolt load. Using the models can therefore lead to a too conservative 
design or an imprudent design that will fail. In [14] a comparison between field experiments, laboratory experiments and FE calculations are presented. The overall findings are that large discrepancies between calculated and measured values of bolt stress are found, the reason is expected primarily to be due to imperfection in real wind turbine connection relative to the laboratory experiment and the FE calculation. Even the presence of an elastic sealant/gasket between the two L-flanges can have a significant influence on the experimental result.

The overall inherent shortcomings of the L-flange can be improved in quite many ways. The reason for choosing the simple L-flange design for the wind turbine towers (as shown in Figure 1) is related to the price, both in relation to production and inspection. The present paper therefore focuses on moderate design modifications of the original simple design for improving the strength.

The paper is organized as follows. In Section 2 the L-flange FE calculation is presented including the analytical curve-fitted result that can be used to estimate the bolt load (the transfer function). Section 3 describes some simple design modifications and discuss the influence on the strength.

\section{Bolt force transfer function}

For fatigue strength estimation of bolts in a L-flange connection it is not enough only to find the normal bolt force as presented in many papers on the subject. The bending moment is also important because it is the maximum stress in the bolt that controls the strength. Depending on the external load size and the flange design the bending moment can have a significant influence on the maximum stress. A derivation is therefore made for both in the following.

The essential first part of the transfer function is found from the bolt stiffness and the member stiffness. The stiffnesses can be estimated using [2]. In [3] the stiffness for the concentrically 
bolted connection is discussed and it is shown how the stiffness estimation found in the literature has a rather large variation, and a new stiffness estimate is proposed based on curve fitted FE results. The stiffness was in this paper found using the elastic energy determined from the FE analysis and the same is done for the eccentric case.

The elastic energy method for finding the stiffness is shortly described. The stiffness is evaluated using the finite element method (FEM), and the numerical tool used is the COMSOL program ([15]). Assuming linearity the stiffness is constant and defined as (one dimensional)

$$
K_{s}=\frac{F_{s}}{D_{s}}
$$

where $F_{s}$ is the force and $D_{s}$ is the corresponding deflection. For a distributed load the stiffness can be estimated using the total elastic energy $U$, which equals twice the strain energy in the linear case $U_{\epsilon}=U / 2$. The linear solution to a FE problem can be stated as

$$
\{F\}=[K]\{D\}
$$

where $\{F\}$ is the nodal load vector, $\{D\}$ the corresponding nodal deflection and $[K]$ the stiffness matrix. We may express the force as

$$
F_{s}=\|\{F\}\|_{2} \Rightarrow\{F\}=F_{s}\{v\}
$$

where $\{v\}$ is a unit vector and $F_{s}$ is the load size. The displacement in the force direction is given by

$$
D_{s}=\{v\}^{T}\{D\}
$$


From the FE calculation the total elastic energy is given by

$$
U=\{F\}^{T}\{D\}=F_{s}\{v\}^{T}\{D\}=F_{s} D_{s}
$$

by substitution we find

$$
K_{s}=\frac{F_{s}}{D_{s}}=\frac{F_{s}^{2}}{U}
$$

We can therefore estimate the bolt and the compressed members stiffness from the preload force $F_{V}=F_{s}$ and the elastic energy in the bolt, $U_{b}=U$, and in the members, $U_{m}=U$, respectively. However for the eccentric load the external load does not act as the preload, it also add additional bending to the bolt.

From the discussion in the introduction the overall force transfer function shape is known. The initial part is linear, because the boundary condition, i.e., the contact area does not change. The most easy way to establishing the linear function is to load the L-flange with a small external load as compared to the preload say $1 \mathrm{kN}$, the slope is then directly given as the increase in bolt load relative to the size of the applied external load.

Initially we will apply the same example as found in [11], the data is (refer to Figure 1)

$$
t=70 \mathrm{~mm}, \quad a=69 \mathrm{~mm}, \quad b=128 \mathrm{~mm}, \quad s=24 \mathrm{~mm}
$$

bolt size $M 36$ class 10.9 , i.e. ultimate tensile strength $\sigma_{u t}=1000 \mathrm{MPa}$ and yield stress $\sigma_{y}=$ $900 \mathrm{MPa}$. The radius of bolt circle $R=1.305 \mathrm{~m}$ and the number of bolts in the flange is $n=80$. The example is therefore slightly modified when compared to the original example which has a constant width of $103 \mathrm{~mm}$. 


\subsection{FE details}

The details about the FE, i.e. how the model is build and the assumptions made are important. In Figure 2 the FE model is shown together with a mesh. The element used in the analysis is tetrahedrals with a quadratic displacement assumption. The number of degrees of freedom vary for the different models used in the paper but models with approximately 40000 degreed of freedom are sufficient. Mesh refinements with up to 250000 degrees of freedom are found to only have insignificant differences related to the bolt normal load and bolt bending.

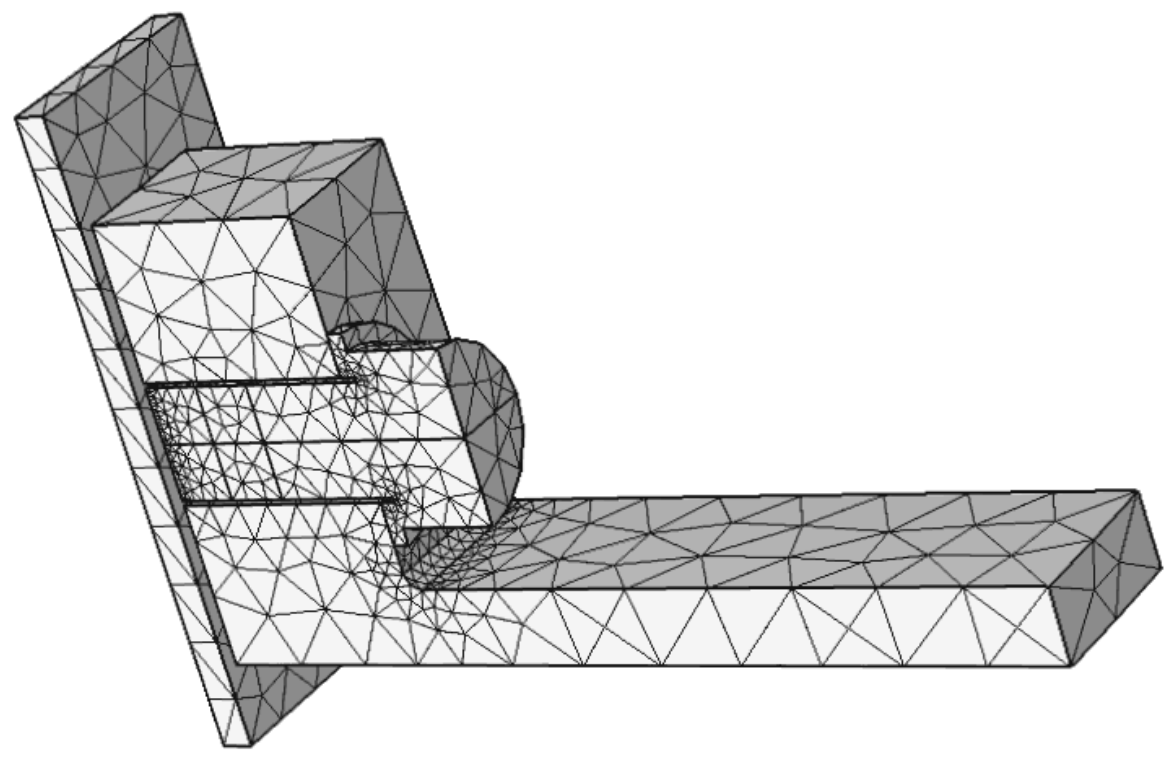

Figure 2: A FE mesh of L-flange and bolt.

As seen only one quarter of the bolt and L-Flange connection supported by the bolt is included in the model (half of the connection is modelled as a rigid plate). This can be done due to assumed symmetry in the flange and bolt. Contact analysis is performed between the washer and the flange and between the flange and the illustrated plate that is assumed to be rigid, i.e. the washer is assumed to be and integrated bolt part. Friction between the washer and the flange is modelled as static coulomb friction with a coefficient of friction $\mu=0.1$.

$$
F_{t} \leq \mu F_{n}
$$


i.e. the maximum traction force $F_{t}$ is given by the normal force $F_{n}$ and the friction coefficient. The friction coefficient used has been changed to $\mu=0.2$ which did not cause any significant change in the derived quantities and therefore $\mu=0.1$ is used in all computations. The washer size is selected according to the standard for a $M 36$ bolt. For this model to be valid the tower wall should be uniformly loaded. In the real case where the wind turbine tower is loaded by both bending and torsion the stress will vary. But due to large number of bolts in the flange (typically larger than 80) the variation in the stress on the highest loaded bolt to the adjacent bolt is so small that the assumption of constant stress and thereby symmetry is valid.

The solution strategy is; first the FE contact problem of finding preload deformations of the bolt and L-flange is solved, i.e. with zero external load. From this deformed configuration the external load is gradually increase and the contact problem is solved in each iteration step. For the standard mesh with 40000 degrees of freedom the computation time for finding the load transfer function on a standard PC is 1 hour. For the most refined models (used for converges check) the computation time is 10 hours.

\subsection{FE example}

In the calculation the bolt preload size is taken from [11], the value is $F_{V}=510 \mathrm{kN}$ corresponding approx. to $70 \%$ of the maximum static bolt strength. With the shown FE model and the given size of bolt and flange the stiffness ratio is given by

$$
\Phi=\frac{K_{b}}{K_{b}+K_{m}}=\frac{U_{m}}{U_{m}+U_{b}}=0.16
$$

This ratio is however not very accurate and the real transfer function between external load and bolt load depends highly on the point of attack of the external load as it was discussed in [5]. In [11] it is proposed that a rough estimate is to use $\Phi=0.06$. However, even this value 
might be an overestimate. For the given example the ratio can easily be established by applying a small external load say $F_{A}=10 \mathrm{kN}$ and relate this directly to the change in bolt load $F_{B}$, i.e.

$$
\Phi=\frac{\Delta F_{B}}{F_{A}}=\frac{F_{B}-F_{V}}{F_{A}}=0.023
$$

This ratio between the external load and the bolt load is very favorable, but the ratio only holds for small external load values where the contact area between the flanges is constant. By increasing the external load the transfer function given in Figure 3 is determined. The preload should be selected as high as possible in order to keep the amplitude of the bolt load as small as possible but so that we are below yielding. Selecting a lower value of the preload will not have a positive effect on the connection because we will only lower the linear asymptote for the initial part of the load transfer function the second asymptote will stay the same and for the same external load variation the amplitude in the bolt will increase.

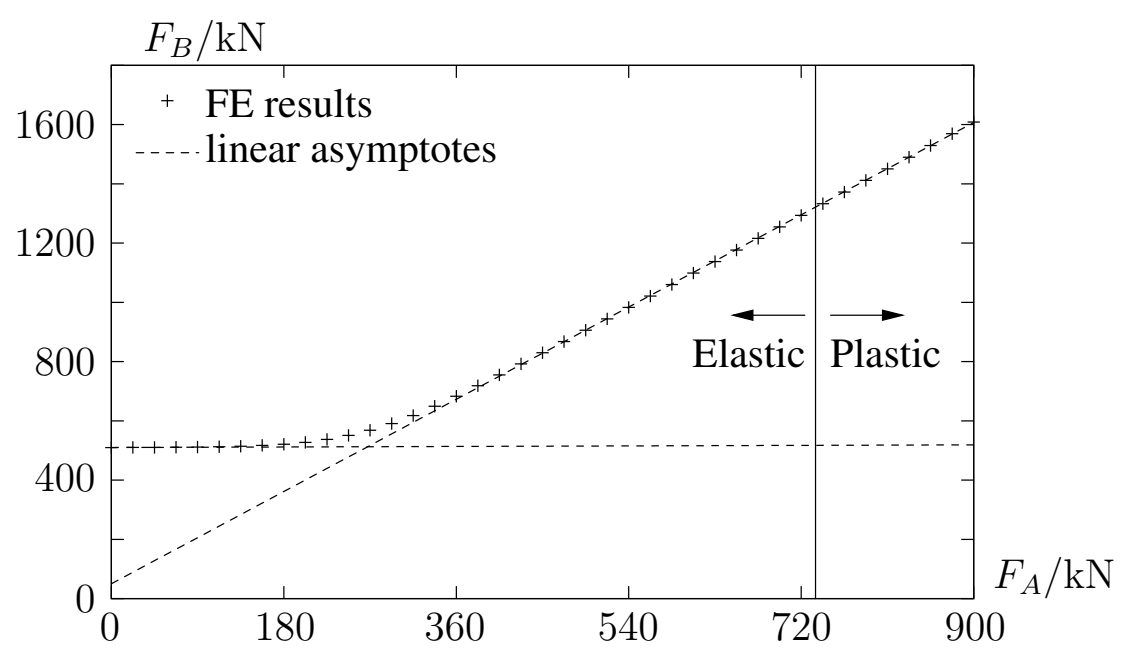

Figure 3: Bolt normal load transfer function, the curve is not valid in the plastic range.

The overall load curve shape is seen in Figure 3. Linear elasticity is assumed i.e. the effect of plasticity is not taken into account, in Figure 3 the ultimate load is too high for the assumption of elasticity to be valid. The maximum allowable load on the bolt depends on the load being 
static or dynamic. If the load is assumed to be static then the maximum load (for this specific case) is

$$
F_{B}^{\max }=A_{s} \sigma_{y}=735 \mathrm{kN}
$$

In relation to fatigue the maximum load is smaller, assuming that the external load varies between $F_{A}^{\min }=0$ and $F_{A}^{\max }$ the maximum bolt load can be estimated. Under the assumption that the Goodman line is flat (in a Goodman diagram), i.e. that it is only the force amplitude that influence the strength and assuming that the stress is below the yield stress, we find

$$
F_{B}^{\max }=F_{V}+A_{s} 2 \sigma_{a}^{\max }=F_{V}+A_{s} 2 \frac{\sigma_{e}}{K_{f}}=619 \mathrm{kN}
$$

where $\sigma_{a}$ is the amplitude stress, $\sigma_{e}$ endurance limit for amplitude stress, $K_{f}$ fatigue stress concentration factor. In the calculation the following have been used; $\sigma_{e}=0.2 \sigma_{u t}$ and $K_{f}=3$. The selected fatigue stress concentration factor corresponds to the normally selected value for rolled thread when the strength ISO class is greater than 6.6 , i.e. the stress concentration factor is related to the stress at the thread. In the FE calculation the focus is on the normal load and the bending moment on the bolt. The finer details of the stress at the points of maximum stress are not in focus they are accounted for by the use of the fatigue stress concentration factor.

The load transfer function for the working range of dynamic loading is given in Figure 4. To validate the results of the present paper FE results from [11] are also shown in the figure. The models are not completely identical, in [11] the flange has a constant width of $103 \mathrm{~mm}$ while in the present paper the flange are modeled as a radial slice, the width at the bolt radius is 102.5mm. Although there are small differences the results compares very well. In [11] further comparison of the results can be found. 


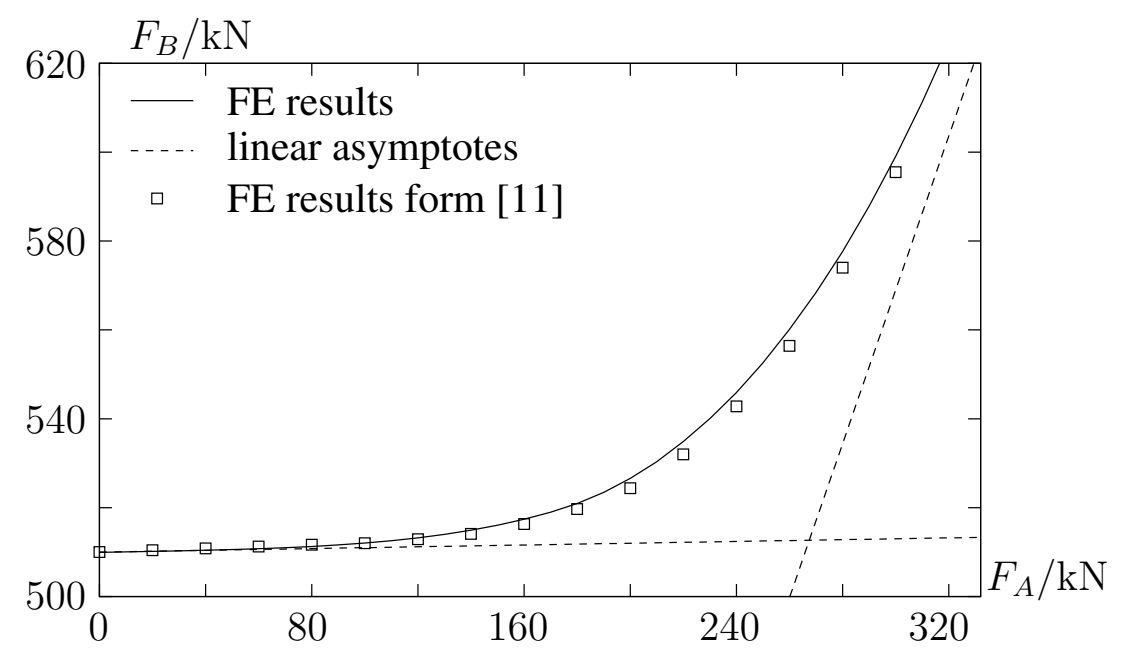

Figure 4: Feasible range of bolt normal load.

In Figure 4 the non-linear transition from one linear asymptote to the second linear asymptote is shown for the limited range of the external load (working range). The reality is even worse than described here due to the bolt bending. The change in bending moment at the symmetry plane (Contact plane between the two L-flanges) is shown in Figure 5. It is seen that the shape of the bending moment loading curve has a similar shape as found for the normal load.

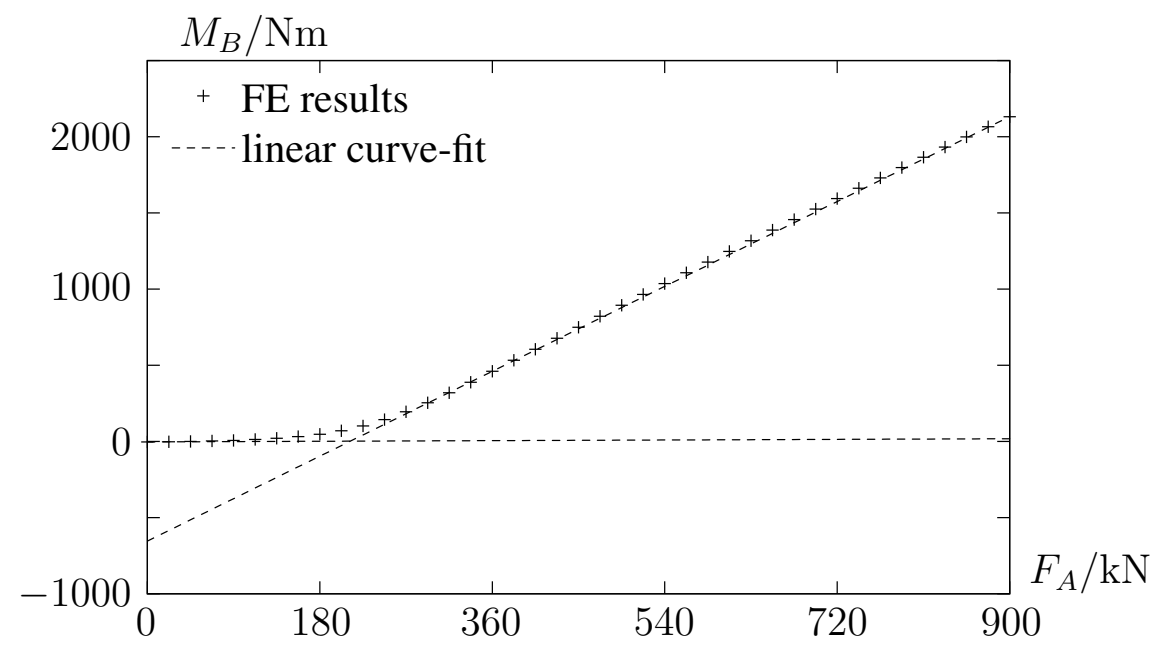

Figure 5: Bolt bending moment transfer function. 


\subsection{Generalizing the results}

The FE results can be used for determining an analytical expression for the bolt normal force and bending moment. Due to the simple response curve shape it is relatively simple to specify an analytical curve-fit. The primary parameters that needs to be established are those that define the initial and the final asymptote $\left(F_{B i}\right.$ and $\left.F_{B f}\right)$

$$
\begin{aligned}
& F_{B i}=\alpha_{n i} F_{A}+\beta_{n i} \\
& F_{B f}=\alpha_{n f} F_{A}+\beta_{n f}
\end{aligned}
$$

For the normal load we have that $\alpha_{n i}=\Phi$ and $\beta_{n i}=F_{V}$.

To curve-fit the transfer function it is selected to use a cubic Bézier curve. The four points that defines the Bézier curve are selected as

$$
\left\{P_{0}\right\}=\left\{\begin{array}{c}
0 \\
\beta_{n i}
\end{array}\right\}, \quad\left\{P_{1}\right\}=\left\{P_{2}\right\}=\left\{\begin{array}{c}
x_{1} \\
y_{1}
\end{array}\right\}, \quad\left\{P_{3}\right\}=\left\{\begin{array}{c}
x_{2} \\
y_{2}
\end{array}\right\}
$$

where the following values can be used

$$
\begin{aligned}
& x_{1}=-\frac{\beta_{n f}-\beta_{n i}}{\alpha_{n f}-\alpha_{n i}} \\
& x_{2}=\gamma x_{1} \\
& y_{1}=\alpha_{n f} x_{1}+\beta_{n f} \\
& y_{2}=\alpha_{n f} x_{2}+\beta_{n f}
\end{aligned}
$$

In order to have a good and preferable not too conservative curve-fit the value of $\gamma$ should 
be selected to fit the FE results. It is not possible due to the many design parameters to select a given $\gamma$ value that fits all design cases.

The curve-fit is in parametric form given analytically as

$$
\left\{\begin{array}{c}
F_{A} \\
F_{B}
\end{array}\right\}=(1-u)^{3}\left\{P_{0}\right\}+3(1-u) u\left\{P_{1}\right\}+u^{3}\left\{P_{3}\right\}, \quad u \in\left[0 ; \gamma x_{1}\right]
$$

outside the range the bolt normal load is given by (15).

If it is desired to have the normal force, $F_{B}$, directly as a function of the external load, $F_{A}$, this can be found by a rearrangement.

$$
\begin{aligned}
& c_{1}=\frac{F_{A}}{x_{2}} \\
& c_{2}=4 c_{1}-12 c_{1}^{2}+8 \gamma^{-3}+4 \sqrt{c_{1}^{2}+4 c_{1} \gamma^{-3}-6 c_{1} \gamma^{-2}+4 \gamma^{-3}-3 \gamma^{-4}} \\
& u=0.5 c_{2}^{1 / 3}+2 \gamma^{-1}\left(c_{1}-1\right) c_{2}^{-1 / 3}+\gamma^{-1} \\
& F_{B}=\left\{\begin{array}{cc}
\beta_{n i}+3(1-u) u\left(y_{1}-\beta_{n i}\right)+u^{3}\left(y_{2}-\beta_{n i}\right) & , \\
\alpha_{n f} F_{A}+\beta_{n f} \leqq \gamma x_{1}
\end{array}\right. \\
& \quad, \quad F_{A} \geq \gamma x_{1}
\end{aligned}
$$

The specific curve-fit has the same slope as the asymptotes at the two end-points, the same type of curve where we can control the slope at the two end-points can also be used in optimization for interpolation functions see e.g. [16]. It should be noted that the assumption behind (20) is linear elasticity which is not valid for high values of $F_{B}$.

For the bending moment the same curve-fit can also be used here. The two linear asymptotes are defined as. 


$$
\begin{gathered}
M_{B i}=\alpha_{b i} F_{A}+\beta_{b i} \\
M_{B f}=\alpha_{b f} F_{A}+\beta_{b f}
\end{gathered}
$$

For the bending moment a good estimate is to use $\alpha_{b i}=0$ and $\beta_{b i}=0$, and in the calculations $\alpha_{n}$ and $\beta_{n}$ are exchanged with $\alpha_{b}$ and $\beta_{b}$ so that, i.e., $x_{1}$ is given by

$$
x_{1}=-\frac{\beta_{b f}-\beta_{b i}}{\alpha_{b f}-\alpha_{b i}}
$$

For the specific example, Figure 6 show the FE results and the analytical curve-fit. The curve-fit matches the numerical results very well.
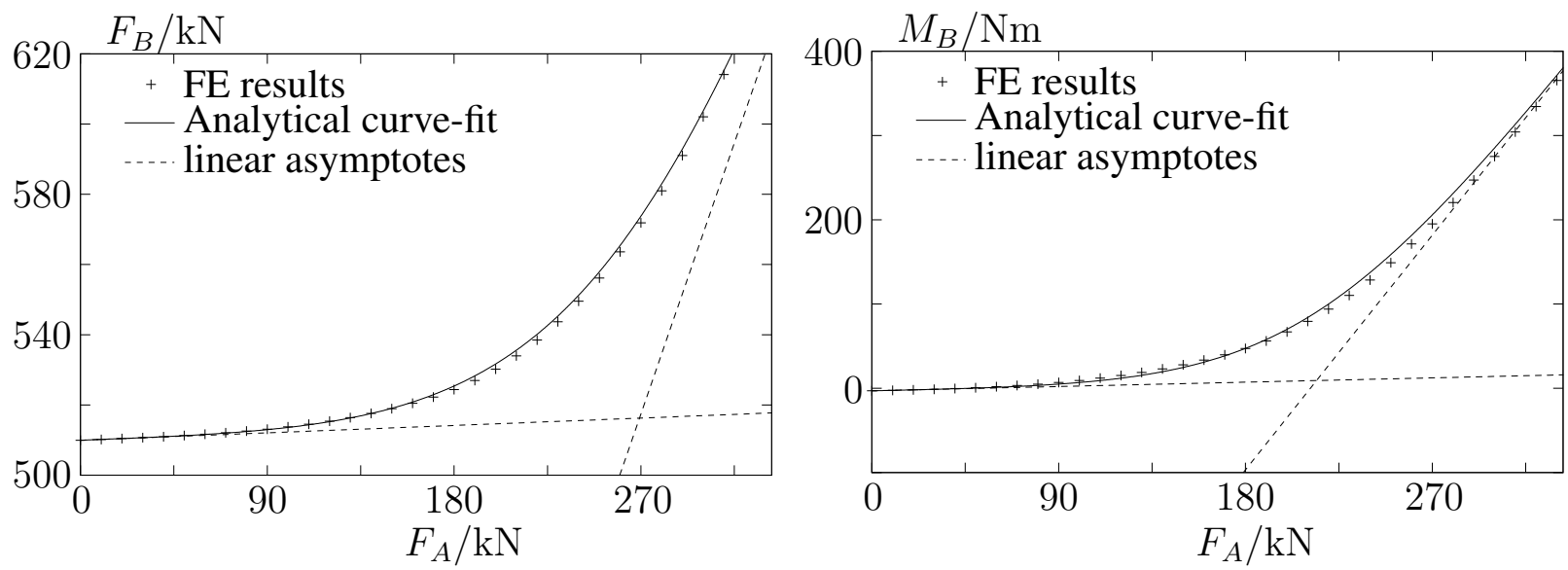

Figure 6: Analytical curve-fit of the bolt normal load and bolt bending moment.

In estimating the L-flange connection fatigue life it would be practical if the amplitude bolt stress level could be established easily. The most exact load curves evaluation is found by a FE analysis of a given connection. The evaluation does not need to be computational demanding since we primarily need to establish the linear asymptotes for the normal load and the bending 
moment. In order to get a conservative estimation we might need a few extra point through the load history to select a suitable $\gamma$ parameter value.

An estimate for the normal load curve (the two asymptotes) can be found using the following: The first asymptote can be estimated directly assuming that the preload $F_{V}$ is given. The value of $\Phi$ can be evaluated using a FE calculation (the most accurate method), or an estimated value like $\Phi=0.06$ suggested in [11] or even $\Phi=0$. It might also be derived from formula in [2]. The second asymptote can not be found so easily. In Figure 7 we show the variation in $\alpha_{n f}$ as a function of $a$ for different values of $b$.

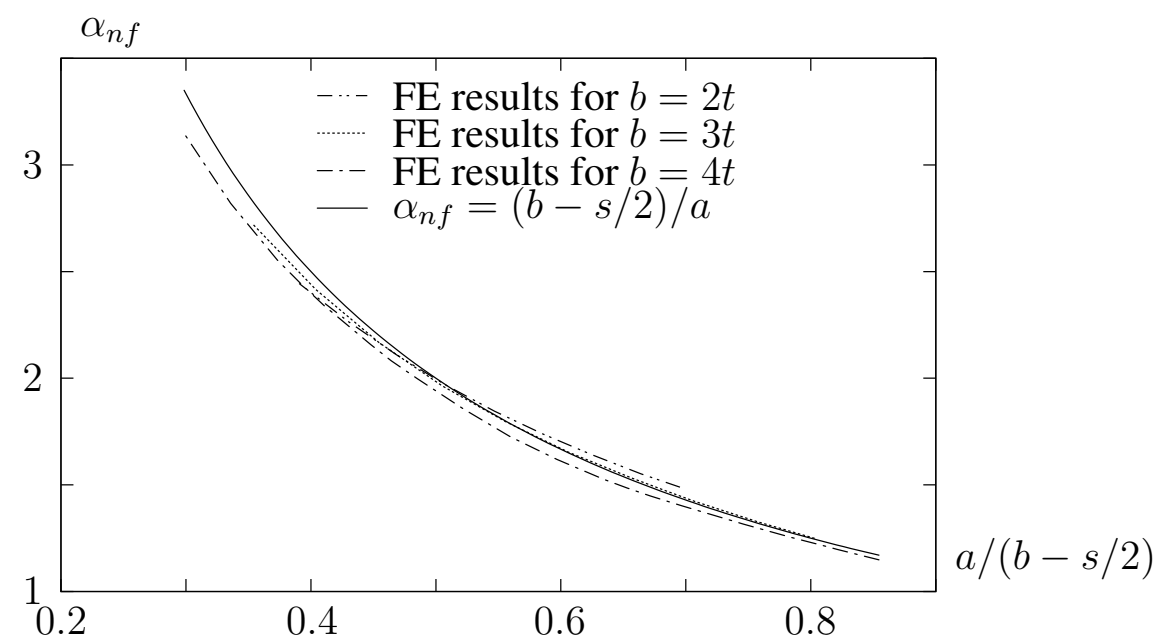

Figure 7: $\alpha_{n f}$ as a function of bolt position for different values of $b$ (see Figure 1).

In Figure 7 we see that a good estimate for $\alpha_{n f}$ is given by

$$
\alpha_{n f}=\frac{b-s / 2}{a}
$$

In Figure 8 the numerical result for the $\beta_{n f}$ value is given for different flange width values $b$. From Figure 8 it is difficult to make some general conclusion, with a too high beta value choice the estimated curves for the bolt normal load will be conservative. We see from the figure that if the flange width is in the normal range, i.e. $b<3 t$, then $\beta_{n f}$ can be selected as 


$$
\beta_{n} \approx 0.1 F_{V}
$$

Selecting the obvious choice $\beta_{n f}=0$ will clearly be an underestimate and the found bolt normal load values will not be conservative.

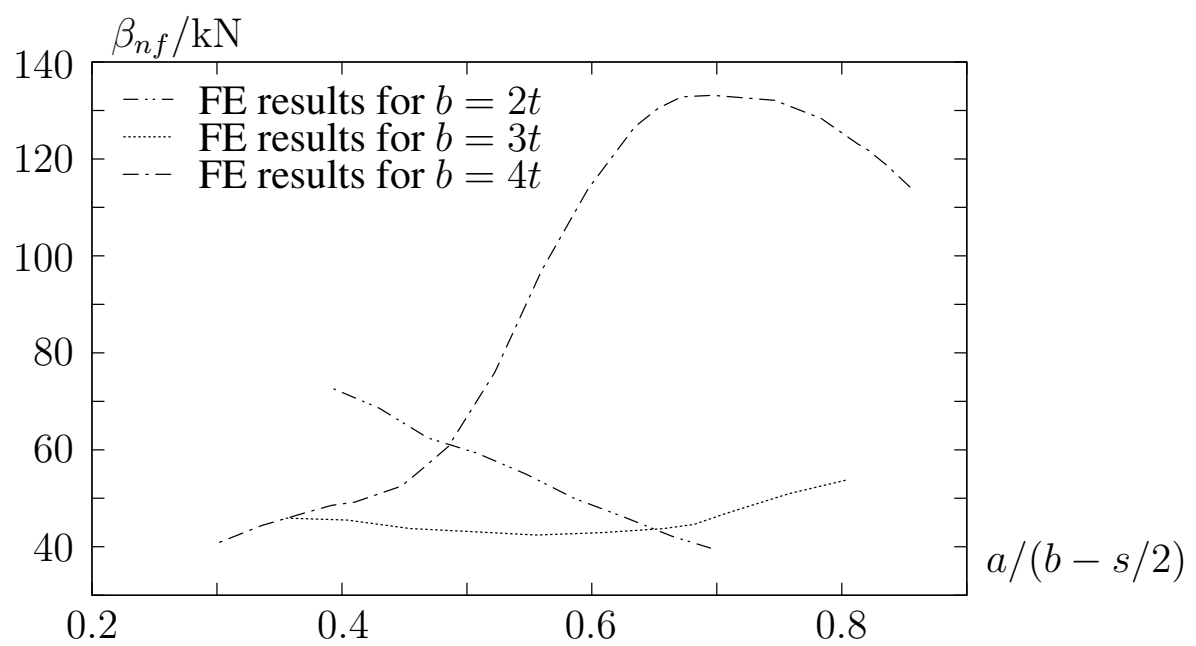

Figure 8: $\beta_{n f}$ as a function of bolt position for different values of $b$ (see Figure 1).

We notice that the strongest design is achieved for larger values of $a$ and $b$, i.e., the bolt should be placed as close to the wall as possible (limited by the standard for space around bolt heads) and the flange width should be large.

For the bolt bending moment the curve can as discussed previously also be estimated by a Bézier curve if the two asymptotes for the bending moment are known. In Figure 9 the numerical results for the $\alpha_{b f}$ and $\beta_{b f}$ values are given for different flange width values $b$.

From Figure 9 it is difficult to establish general values, we are in this case forced to make specific FE analysis of a given design.

Modifying the design such that $b-a=46 \mathrm{~mm}$ and keeping the 80 bolts at the bolt radius $R=1.305 \mathrm{~m}$ we have placed the bolt as close to the wall as possible and as close to each other as possible (limited by the standard for space around bolt heads). In Figure 10 the values defining 
FE results for $b=2 t$
FE results for $b=3 t$
FE results for $b=4 t$

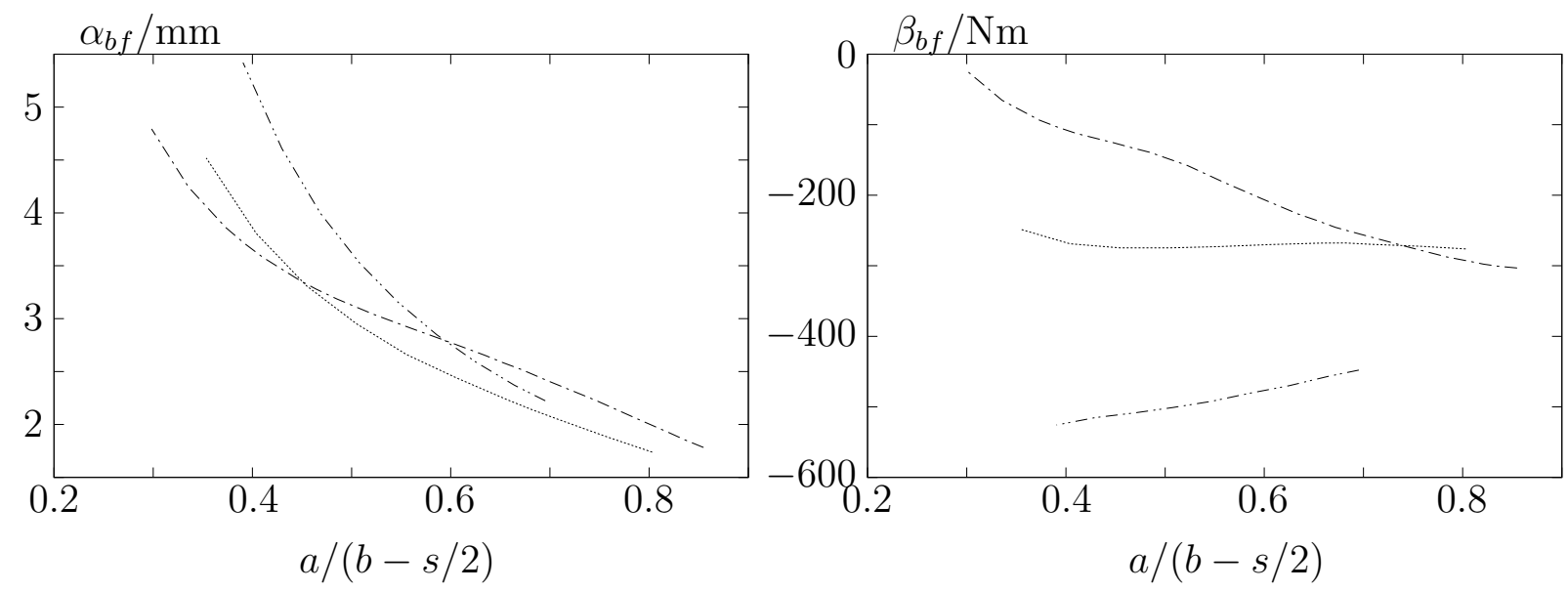

Figure 9: $\alpha_{b f}$ and $\beta_{b f}$ as a function of bolt position for different values of $b$ (see Figure 1).

the asymptotes given in (15) and (22) are given for different values of $a$. It is noted that the values converge for large $a$ values.
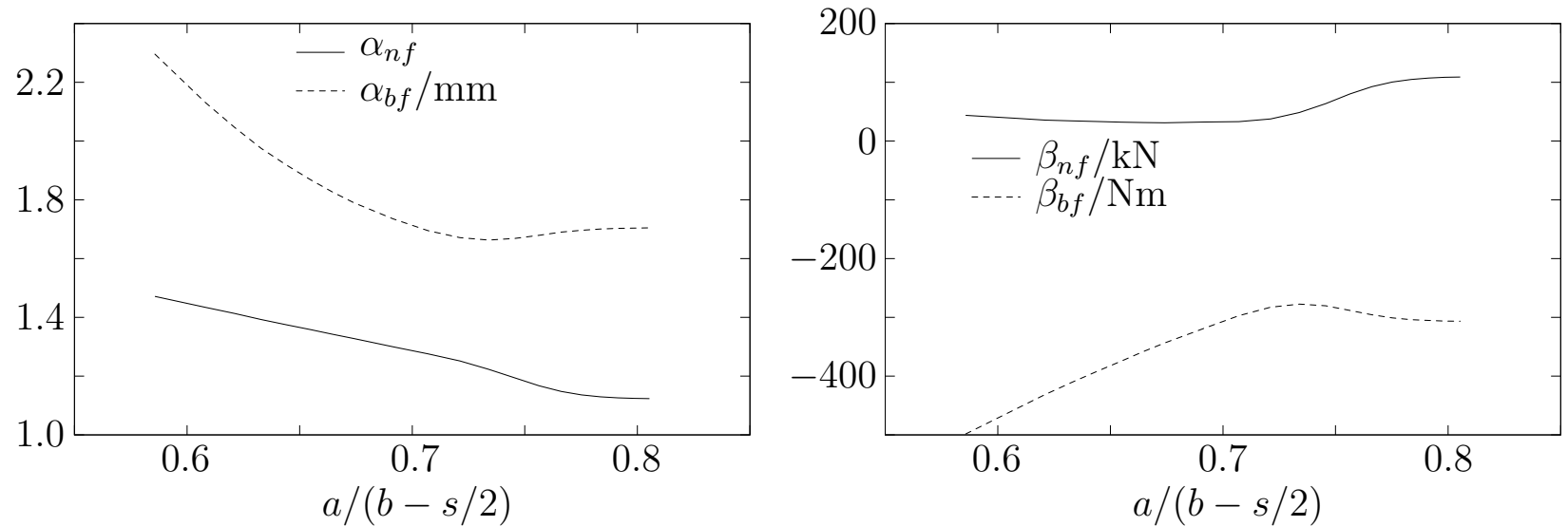

Figure 10: $\alpha_{b f}$ and $\beta_{b f}$ as a function of bolt position for different values of $b$ (see Figure 1).

If we assume that the normal load and bending moment at $F_{A}=500 \mathrm{kN}$ can be given by (15) and (22) we can plot the maximum nominal normal stress in the bolt as a function of $a$, using the values for the asymptotes in Figure 10

$$
\sigma_{\text {nom }}=\sigma_{\text {nom }}^{N}+\sigma_{\text {nom }}^{B}=\frac{\alpha_{n f} 500 \mathrm{kN}+\beta_{n f}}{\frac{\pi}{4} 0.036^{2} m^{2}}+\frac{\alpha_{b f} 500 \mathrm{kN}+\beta_{b f}}{\frac{\pi}{32} 0.036^{3} m^{3}}
$$

where $\sigma_{\text {nom }}^{N}$ is the nominal normal stress due to the normal load and $\sigma_{\text {nom }}^{B}$ is the nominal normal 
stress due to the bending moment.

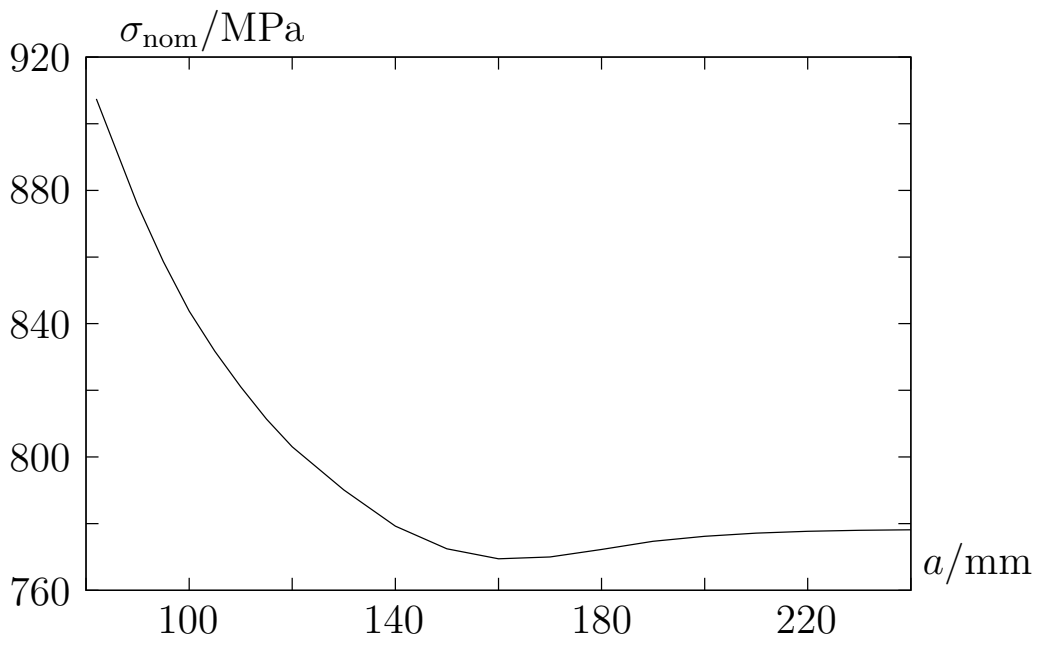

Figure 11: Maximum nominal normal stress in bolt as a function of flange width parameter $a$.

From Figure 11 we see a minimum stress value for $a=160 \mathrm{~mm}$. This corresponds to a revised design with the data:

$$
t=70 \mathrm{~mm}, \quad a=160 \mathrm{~mm}, \quad b=206 \mathrm{~mm}, \quad s=24 \mathrm{~mm}
$$

bolt size, $M 36$, bolt radius, $R=1.305 \mathrm{~m}$, and number of bolts in the flange, $n=80$, is the same as for the original design.

Selecting this design relative to the original, results in normal load and bending moment improvements as seen in Figure 12.

The resulting maximum nominal normal stress for the two designs is given in Figure 13. In the figure the ratio of the normal stress due to the bending moment relative to the stress due to the normal load is also shown. It can be noted that for high external load values the contribution from the bending moment should not be neglected.

The shown revised L-flange design shows the range of improvement that can be expected if the L-flange topology is kept as shown in this section. The reason for choosing this simple 

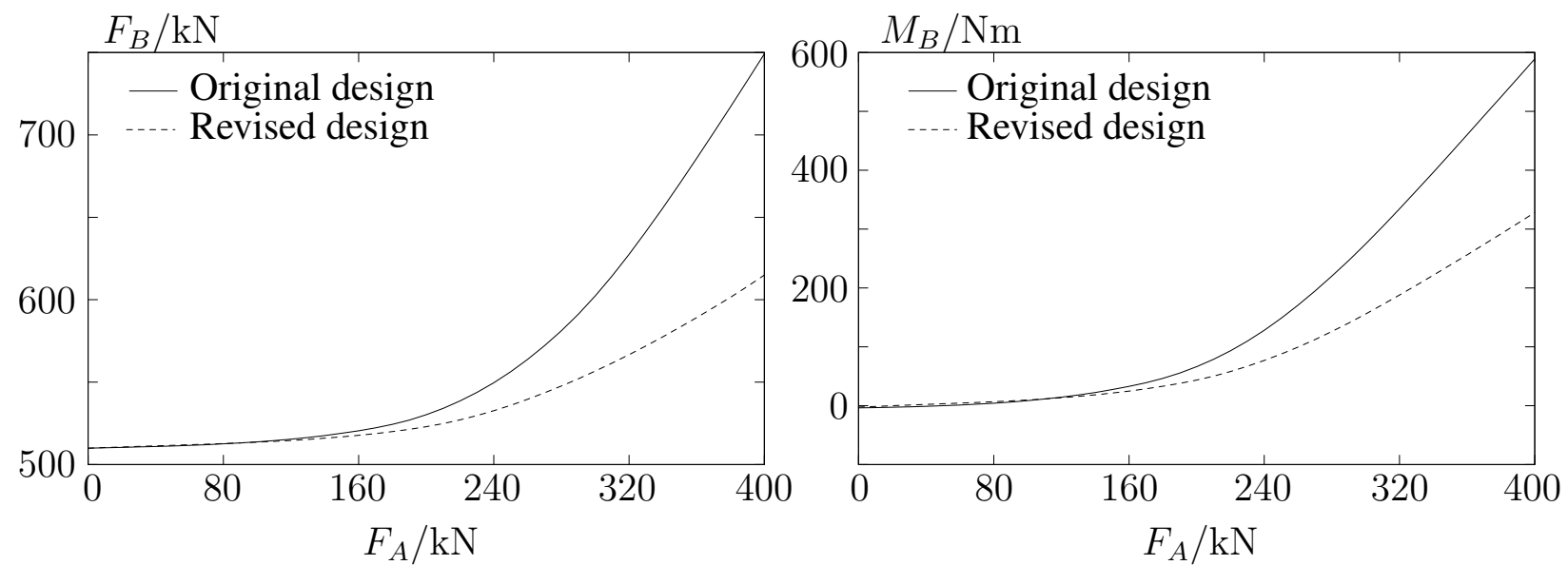

Figure 12: Transfer function for bolt normal load and bending moment for original design and revised design.
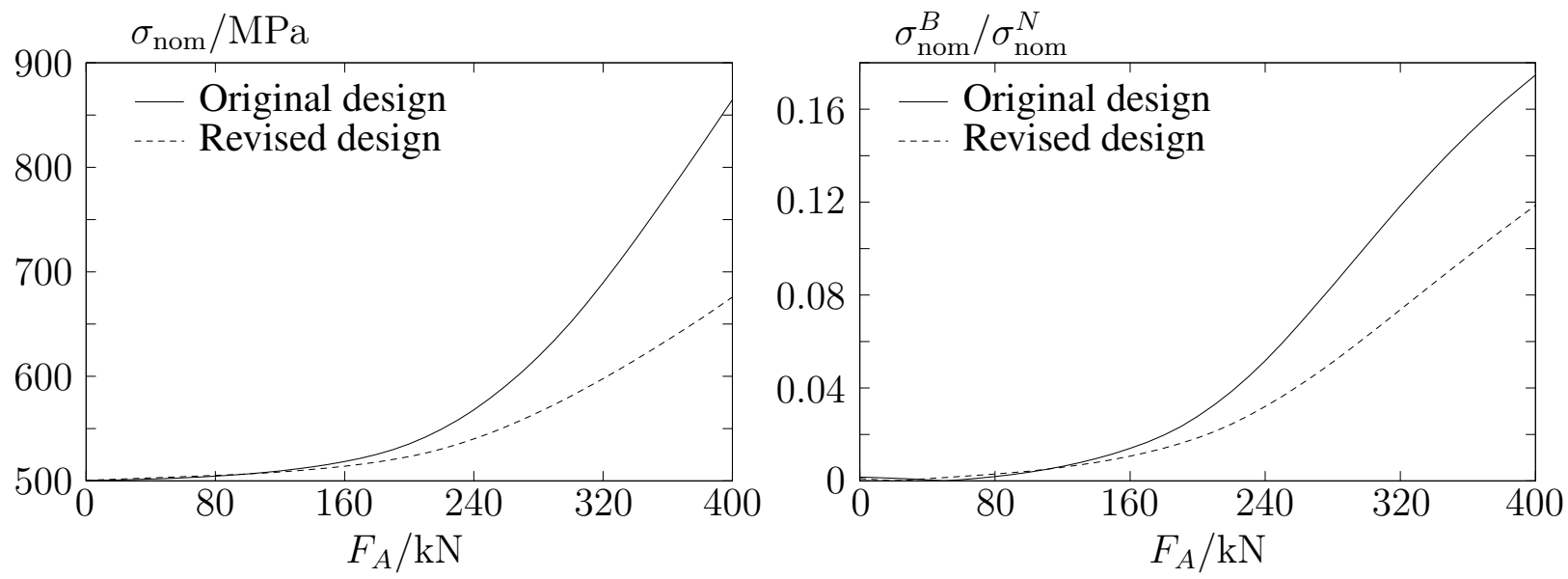

Figure 13: Left: Maximum nominal normal stress in bolt for revised and original design. Right: Ratio between normal stress from bending moment and normal stress from normal load.

design must be the cost of production and/or the assembly method. The examples show that the bolt should be placed as close to the wall as possible, this is limited by the selected assembly method being a hand tool or hydraulic. In the next section some simple design modifications that improves the design further are discussed.

\section{L-flange design modification}

In this section different L-flange design modifications are investigated in order to improve the connection strength. Overall the main problem of the connection is the eccentric load; only 
for relatively small loads, where the contact area does not charge, will the connection take advantage of the preload. For higher loads a highly non-favorable load transfer to the bolt is controlled by the moment equilibrium as discussed previously. The best design would be achieved by changing the L-flange into a T-flange bolted on both the inner an outer flange. This is however not practical for the wind turbine towers due to assembly and transportation issues.

One way of transferring the load from tower wall to the L-flange is to add stiffeners as seen in Figure 14. This design change will increase the flange production price. The stiffeners will in themselves improve the design, however in order to fulfill the requirements with respect to spacing around the bolt the number of bolts have to be reduced. This reduction in the number of bolts increases the external load on the individual bolt. The overall conclusion is that the negative effects are stronger than the positive effects and therefore the design with stiffeners has a smaller strength than the design with the maximum number of bolts.

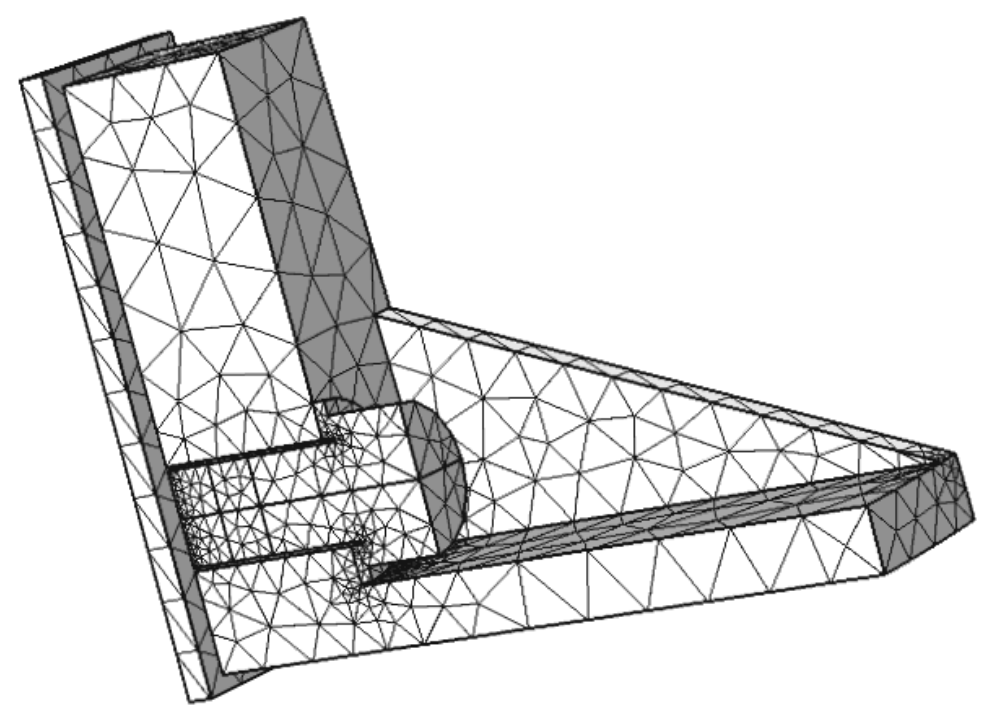

Figure 14: L-flange with stiffener.

An alternative way of improving the design is to improve the flange bending stiffness. In many other design of flange a neck as seen in Figure 15 is used. For the present design where the external loading is primarily tower wall bending the neck design is not beneficial. This is 
primarily due to the negative effect this design has on the moment equilibrium as compared to the design where we put the bolt as close as possible to the tower wall.

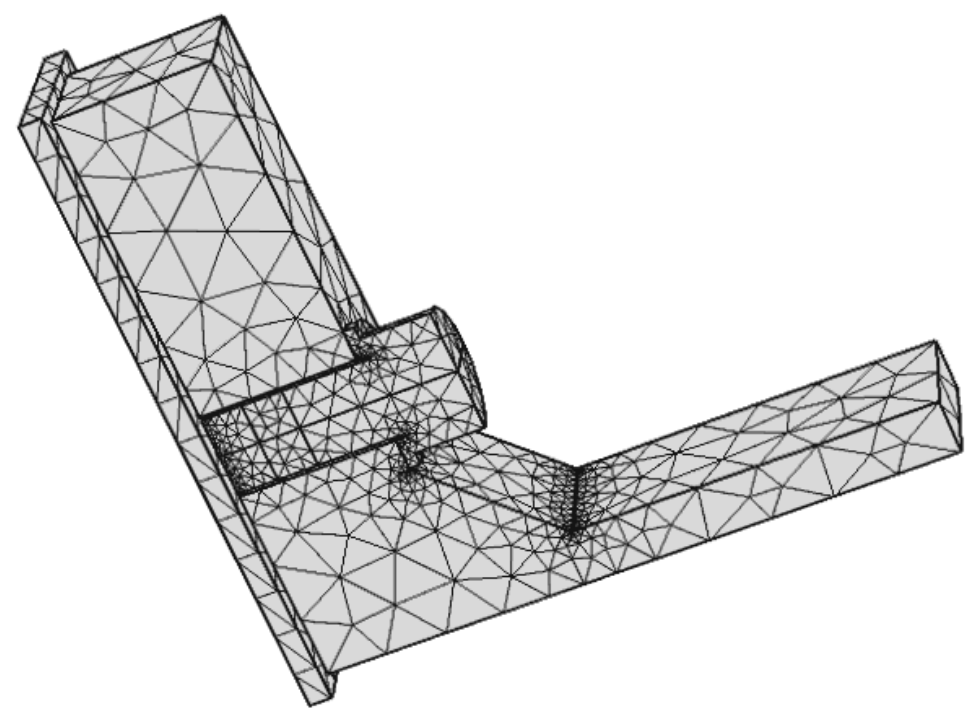

Figure 15: L-flange with added neck.

Design changes to the contact surfaces between the flanges has also been reported in the literature, see e.g. [7] and [1]. In these papers it is reported that the L-flange with a defined smaller contact areas has an improved relationship between external load and bolt normal load. This is also the findings in the present study for e.g. a design as shown in Figure 16, although the improvement is not valid for the whole loading range. The bolt can for this design be placed differently relative to two contact areas. Independently of the bolt placement this kind of design has a sharp change in the load transfer function when there is no longer contact in the contact area at the tower wall. The overall best design is in this case also with the bolt as close to the tower wall as possible. If we examine the normal load transfer function for this design, shown in Figure 17, we find as reported in the literature that this design over a long load range is better than the traditional design, in that the normal load is smaller.

The design in Figure 16 also give rise to a considerable bending moment in the bolt that is substantially larger than for the original design. If we compare the maximum nominal normal 


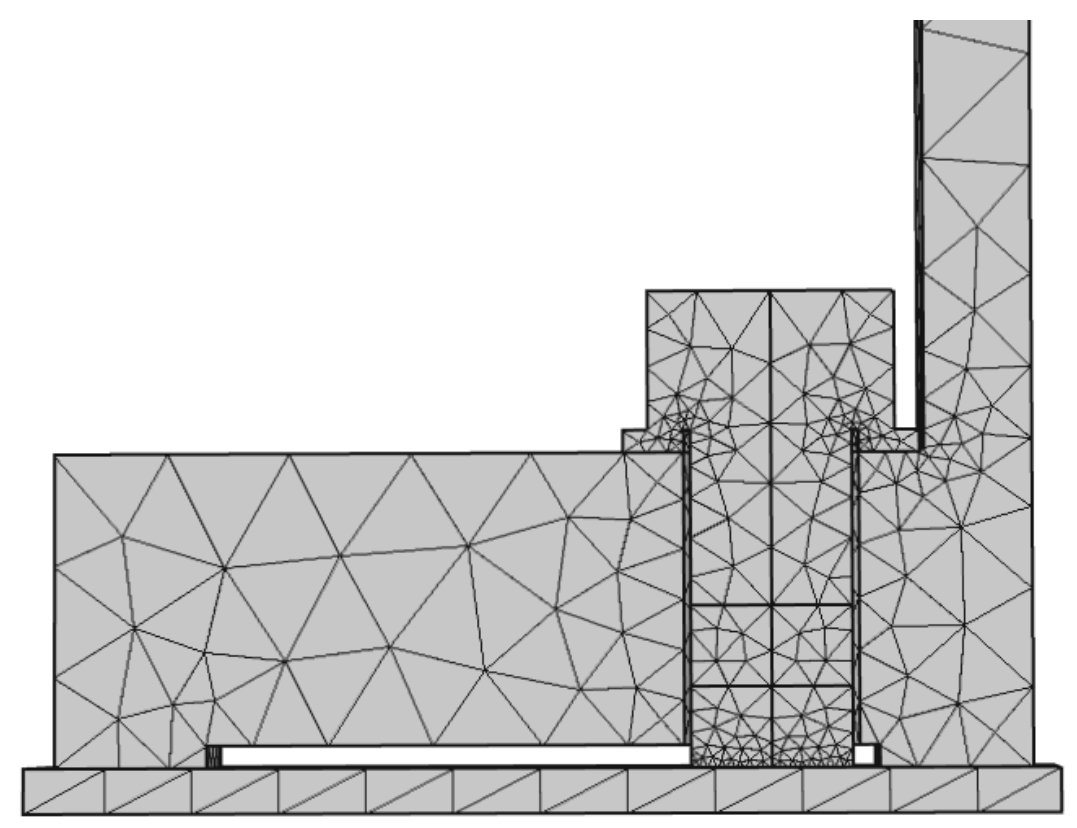

Figure 16: L-flange with reduced contact area.

stress, see Figure 17, we see that only for a relative narrow load range is this design favorable. The influence from the bending moment on the normal stress is directly seen when there is no external load.
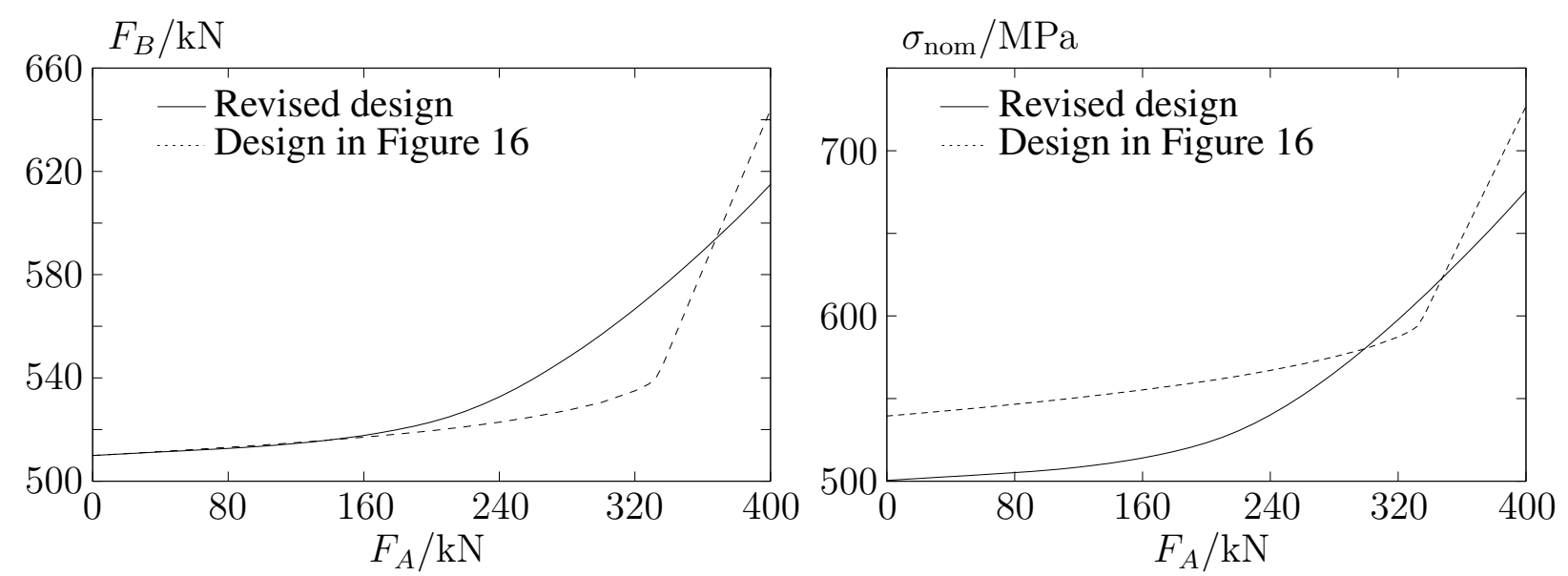

Figure 17: Left: Bolt normal load transfer function for revised design and design with reduced contact area. Right: Maximum nominal normal stress in bolt for the revised design and design with reduced contact area.

The production cost of the design in Figure 16 is larger than the original design, however the extra control with the contact surface might have a positive influence on the tolerances and 
the removal of flaws and imperfections.

The final design change discussed is the simplest one but also the most efficient one for increasing the strength, i.e. to increase the flange thickness whereby the flange bending stiffness is directly improved. The production cost for this design change must be limited to problems related to the increased mass and to the material cost. In Figure 18 the load transfer curves are given for the flange thickness $t=70 \mathrm{~mm}, t=100 \mathrm{~mm}$ and the double size of the original design $t=140 \mathrm{~mm}$.
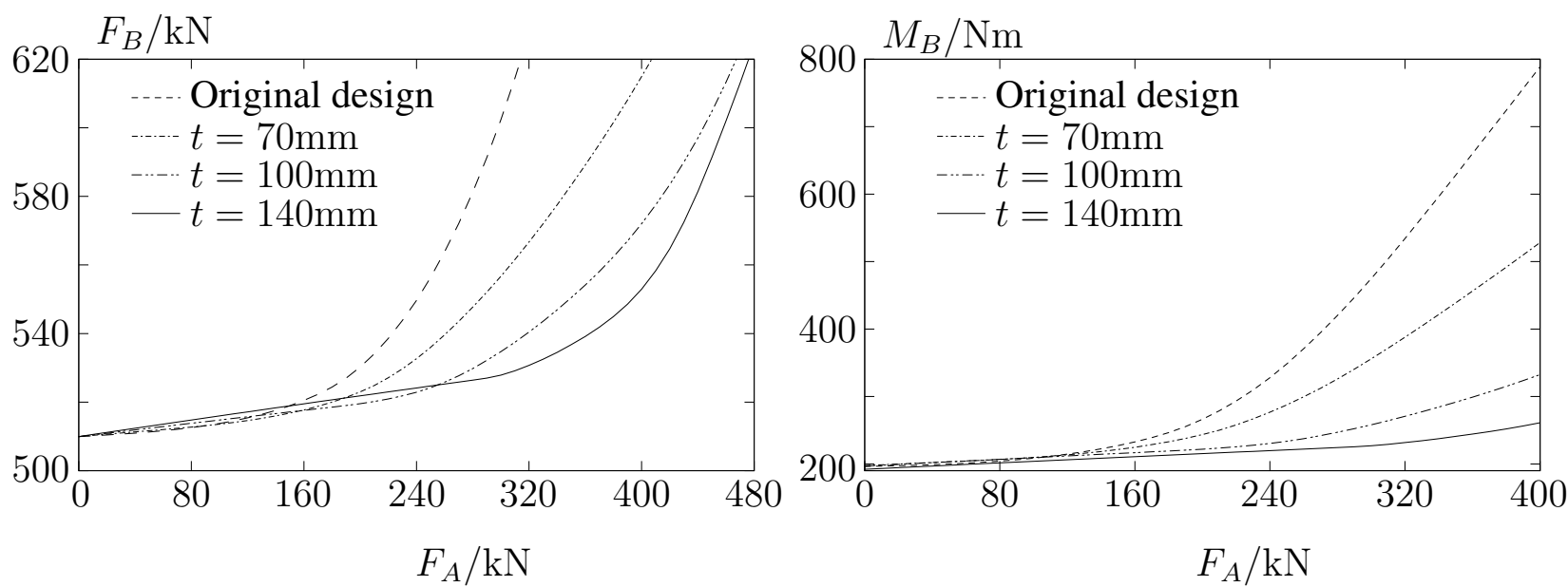

Figure 18: Left: Bolt normal load transfer function for the original design and the revised design with flange thickness $t=70 \mathrm{~mm}, t=100 \mathrm{~mm}$ and $t=140 \mathrm{~mm}$. Right: Bending moment in bolt for the original design and the revised design with flange thickness $t=70 \mathrm{~mm}, t=100 \mathrm{~mm}$ and $t=140 \mathrm{~mm}$.

The design improvement from the design with the increase flange thickness relative to the original design is clearly seen both for the normal load and the bending moment. Figure 19 show the maximum nominal normal stress in bolt as a function of external load. With the assumption that the maximum allowable normal load is $619 \mathrm{kN}$ which corresponds to a maximum normal stress of approximately $630 \mathrm{MPa}$, we see from Figure 19 that compared to the original design the design with flange thickness $t=70 \mathrm{~mm}, t=100 \mathrm{~mm}$ and $t=140 \mathrm{~mm}$ are $23 \%, 55 \%$ and $65 \%$ stronger respectively. These improvements in the L-flange strength are significant. 


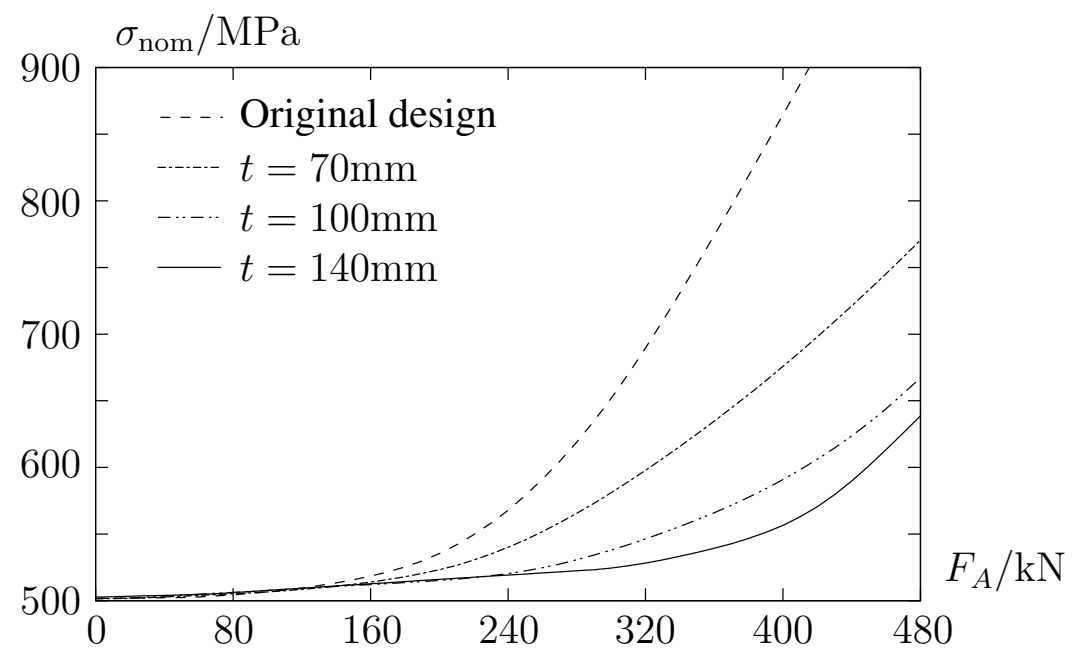

Figure 19: Maximum nominal normal stress in bolt as a function of external load. For the original design and the revised design with flange thickness $t=70 \mathrm{~mm}, t=100 \mathrm{~mm}$ and $t=140 \mathrm{~mm}$.

\section{Conclusion}

L-flange assemblies are from a bolt point-of-view a bad design and when this design is selected anyway it is done due to constraint on the possible layout. The important transfer function between the external load and load in the bolt is shown to have two linear asymptotes in the practical load spectrum of the external load. The load curves can be approximated by a Bézier curve. In order for the analytical curve-fit to be sufficiently accurate, numerical calculations must be performed. Overall values for the asymptotes can be estimated directly in many cases and are presented in the paper.

Following the load curves analysis different L-flange design changes are investigated in the paper. The best design improvement is found by putting the bolt as close to the tower wall as possible. Further significant improvements are found by increasing the flange thickness. Strength improvements of up to $65 \%$ relative to a standard design are reported.

\section{Acknowledgment}


For discussions and suggestions I wish to thank Prof. Peder Klit and Prof. Pauli Pedersen.

\section{References}

[1] Veljkovic M, Feldmann M, Naumes J, Pak D, Simes da Silva L, Rebelo C. Wind turbine tower design, erection and maintenance. Wind Energy Systems: Optimising Design and Construction for Safe and Reliable Operation. 2010;p. 274-300.

[2] VDI 2230 Blatt 1. Systematische berechnung hochbeanspruchter schraubenverbindungen zylindrische einschraubenverbindungen, systematic calculation of high duty bolted joints. Joints with one cylindrical bolt. Beuth-Verlag GmbH, 10772 Berlin; 2003.

[3] Pedersen NL, Pedersen P. On prestress stiffness analysis of bolt-plate contact assemblies. Archive of Applied Mechanics. 2008;78(2):75-88.

[4] Pedersen NL, Pedersen P. Stiffness Analysis and Improvement of Bolt-Plate Contact Assemblies. Mechanics Based Design of Structures and Machines. 2008;36(1):47-66.

[5] Pedersen NL, Pedersen P. Bolt-plate contact assemblies with prestress and external loads: Solved with super element technique. Computers \& Structures. 2009;87(21-22):13741383.

[6] Agatonovic P. Beam model of bolted flanged connections. Engineering Computations (Swansea, Wales). 1985;2(1):21-29.

[7] Schmidt H, Neuper M. Zum elastostatischen tragverhalten exzentrisch gezogener L-stöße mit vorgespannten schrauben, On the elastostatic behaviour of an eccentrically tensioned L-joint with prestressed bolts. Stahlbau, Stahlbau. 1997;66(3):163-168. 
[8] Petersen C. Nachweis der betriebsfestigkeit exzentrisch beanspruchter ringflanschverbindungen, Fatigue strength of eccentric stressed ring flange joints. Stahlbau, Stahlbau. 1998;67(3):191-203.

[9] Lehmann D. Berechnung des nichtlinearen Tragverhaltens gezogener vorgespannter LFlansche. Stahlbau. 2000;69(1):35-54.

[10] Schaumann P, Kleineidam P, Seidel M. Zur FE-Modellierung von zugbeanspruchten Schraubenverbindungen. Stahlbau. 2001;70(2):73-84.

[11] Seidel M, Schaumann P. Ermittlung der Ermdungsbeanspruchung von Schrauben exzentrisch belasteter Flanschverbindungen. Stahlbau. 2001;70(7):474-486.

[12] Pedersen NL. Optimization of Bolt Thread Stress Concentrations. Archive of Applied Mechanics. 2013;83(1):1-14.

[13] Pedersen NL. Overall bolt stress optimization. Journal of Strain Analysis for Engineering Design. 2013;48(3):155-165.

[14] Schaumann P, Seidel M. Ermüdungsbeanspruchung geschraubter Ringflanschverbindungen bei Windenergieanlagen. Stahlbau. 2002;71(3):204-211.

[15] COMSOL AB. www.comsol.se: Stockholm; 1998-2009.

[16] Pedersen P, Pedersen NL. Interpolation/penalization applied for strength design of 3D thermoelastic structures. Structural and Multidisciplinary Optimization, Struct Multidiscip Optim, St Mult Opt, Struct Multidiscip O, Struct Multidiscip Optim, Structural and Multidisciplinary Optimization. 2012;45(6):773-786. 